\title{
Effects of knowledge management on the management of health and social care: a systematic literature review
}

\author{
Tuomas Hujala and Harri Laihonen
}

\begin{abstract}
Purpose - The purpose of this study is twofold. First, it suggests that knowledge management (KM), as an academic discipline and managerial practice, provides valuable perspectives and tools to help health and social care management cope with both existing and future challenges. Second, it reviews the existing evidence on the effects of KM on the management of health and social care. Based on the results of the review, an evaluation framework for the effects of $K M$ is proposed.

Design/methodology/approach - The literature review was conducted using the guidance of the Preferred Reporting Items for Systematic Reviews and Meta-Analyses statement to search the Web of Science and SCOPUS databases. The search terms included "knowledge management", "healthcare" and "effect." Academic articles published between 2010 and 2020 were included.

Findings - The study identifies six main categories among the effects of KM on the management of health and social care as follows: enhanced understanding of customer needs, improved organizational performance, better targeted decision-making, improved quality of service, behavioral or cultural change and improved risk management.
\end{abstract}

Originality/value - This study contributes by summarizing the literature on the effects of KM on the management of health and social care and proposing avenues for future research in this area.

Keywords Knowledge management, Effects, Health care, Social care, Health management

Paper type Research Article

\section{Introduction}

Health and social care is facing formidable challenges worldwide. The costs of care are rising, and in many countries, the population is aging, thereby increasing the need for health and social services. Innovative approaches and models are consequently needed to ensure the availability and quality of services. Thus, the purpose of this article is twofold. First, we follow the knowledge-based view of a firm Grant (1996), Spender (1996) and suggest that knowledge management (KM), as an academic discipline and managerial practice, provides valuable perspectives and tools to help health and social care management to cope with present and future challenges (Von Krogh, 1998; Alavi and Leidner, 2001). Second, we review the prevailing KM approaches and analyze the existing evidence on the effects of KM on the management of health and social care. On the basis of our review, we propose a preliminary framework to determine the effects of KM to support both academics and practitioners in further developing $\mathrm{KM}$ and rendering it more readily applicable to health and social care management. The main contribution of the article is to health and social care, but the results of the review and the discussion presented are also of relevance to researchers and practitioners interested in the impacts of KM on organizational performance.
Tuomas Hujala and Harri Laihonen are both based at the Department of Health and Social Management, University of Eastern Finland - Kuopio Campus, Kuopio, Finland.

Received 6 November 2020 Revised 14 April 2021 8 June 2021

5 August 2021

Accepted 30 August 2021

(C) Tuomas Hujala and Harri Laihonen. Published by Emerald Publishing Limited. This article is published under the Creative Commons Attribution (CC BY 4.0) licence. Anyone may reproduce, distribute, translate and create derivative works of this article (for both commercial and non-commercial purposes), subject to full attribution to the original publication and authors. The full terms of this licence may be seen at http:// creativecommons.org/licences/ by/4.0/legalcode 
Despite over 20 years of KM research and practice, the principal gap persists, relating to capturing the impacts of KM on business performance (Andreeva and Kianto, 2012; Heisig et al., 2016; Inkinen, 2016; Caputo et al., 2019). As Heisig et al. (2016) point out, evidence of the effectiveness of KM would be extremely important to justify the approach in new contexts and to identify the most effective approaches. In theory, much has been expected of KM regarding, for example, competitive advantage (Kogut and Zander, 1992; Nonaka and Takeuchi, 1995; Grant, 1996), innovation (Corso et al., 2001; du Plessis, 2007), organizational learning (Firestone and McElroy, 2004; Spender, 2008) and improved decision-making (McKenzie et al., 2011). In aspiring and balancing these multi-level objectives, KM can be considered to be a mechanism for dealing with organizational ambidexterity, that is, balancing exploitation and exploration (Gupta et al., 2006; Filippini et al., 2012). This is also a mounting challenge for the management of health and social care when the integration of services adds organizational complexity. Several authors (Kaur et al., 2019; Schreyögg and Sydow, 2010) have argued that in a changing operating environment traditional decision-making structures and systems do not work optimally and more flexible organizational forms and knowledge strategies are needed (Laihonen and Huhtamäki, 2020). Nevertheless, empirical evidence regarding the perceived outcomes of various KM initiatives remains scarce. Inkinen (2016) provides a valuable overview of the empirical evidence of the effects of $\mathrm{KM}$ on firm performance, but from the perspective of this article, it is noteworthy that none of the empirical studies reviewed dealt explicitly with health or social care, and also that the public sector, typically involved with the provision of health and social care, was not under investigation in any of the articles reviewed. The research gap in this area is obvious.

As a concept and a practice, KM has increasingly pervaded health and social care organizations in recent decades (Nicolini et al., 2008; Ayatollahi and Zeraatkar, 2020). At the beginning of the millennium, van Beveren (2003) already asked in the title of his article: "Does health care for knowledge management?" and concluded that specific models, tools and techniques are required in the health care sector. Since van Beveren's study, the decades-long debate on health and social care KM has concerned, for example, the barriers and enablers of knowledge sharing (Kim et al., 2011; Mura et al., 2013; Lin and Lo, 2015), the strengths and weaknesses of organizational culture for KM (Rohajawati et al., 2016; Jamshed and Majeed, 2019; Arefin et al., 2020) and the role of technology in supporting the reform of health and social care (Panahi et al., 2016; Antonacci et al., 2017; Fletcher-Brown et al., 2020). The KM literature provides a plethora of theoretical models and frameworks Boder (2006), Sheffield (2008) aiming to help health and social care managers resolve knowledge-related challenges. The various KM initiatives in health and social care can be categorized into three main categories, namely, information technology (IT)-based, socially-based and human-resource driven (Nicolini et al., 2008) and typically concern decision-making support on the one hand and quality and efficiency thresholds on the other (Mohajan, 2016).

The ongoing debates about the nature of knowing, the benefits and pitfalls of specific KM initiatives, as well as the barriers and enablers of KM in health and social care, have been conducted on several levels (Nicolini et al., 2008; Ayatollahi and Zeraatkar, 2020). Kothari et al. (2011) posed a question regarding the applicability of business-driven KM strategies to the health domain and showed that rigorous studies on the effectiveness of such initiatives are lacking. Currie et al. (2008) pointed out the difficulties of knowledge sharing arising from institutional forces and highlighted the cultural and political dimensions of knowledge sharing. Moreover, Lunden et al. (2017) studied the factors facilitating and inhibiting the development of nurses' competency and nurse leaders' role in KM and called for further research on the influence of cultural factors on KM. Despite the increasing body of literature on $\mathrm{KM}$ in health and social care management and some attempts to capture the impacts of KM in this context Tamanna and Sharma (2019), Parast and Golmohammadi (2019) no systematic efforts have been made to categorize these impacts. This article, 
therefore, aims to address this knowledge gap through a systematic literature review and by answering the following research questions:

$R Q 1$. How have the effects of $\mathrm{KM}$ been studied in the management of health and social care?

$R Q 2$. What are the reported effects of $\mathrm{KM}$ on the management of health and social care?

As its main contribution, the article will identify the gaps in our current knowledge and advance the understanding of the prospects for KM to support health and social care management. The article will also suggest some avenues for future research in the area.

The rest of the article is organized as follows: Section 2 describes our research methods and data. Section 3 presents the results of the literature review and Section 4 discusses the main findings. Finally, Section 5 concludes the discussion by proposing avenues for future $\mathrm{KM}$ research in the specific context of health and social care management.

\section{Research methods and data}

Following the "Preferred Reporting Items for Systematic Reviews and Meta-Analyses (PRISMA)" guidelines (Liberati et al., 2009), a systematic literature review was conducted in which we aimed at a considered, reproducible and unbiased outcome, and found systematic literature review to be the most appropriate way to approach the topic (Xiao and Watson, 2017). According to the PRISMA guidelines, the essential steps in a systematic literature review are the following:

- Formulate research questions;

- Select search terms;

- Determine a search strategy to be strictly adhered to;

- Set the inclusion and exclusion criteria;

- Conduct the search;

- Select the articles; and

- Perform a quality check on the articles included in the review study (Moher et al., 2009; Lunden et al., 2017).

\subsection{Search strategy and inclusion criteria}

A systematic search was conducted in the SCOPUS and Web of Science databases in August 2020. To obtain the systematic and comprehensive initial output for later-stage filtering we used the following query: "TITLE-ABS-KEY ("health service*" OR "social service" OR health care OR "health care" OR "social care") AND TITLE-ABS-KEY ("knowledge management" OR "managing knowledge") AND TITLE-ABS-KEY (impact* OR success* OR effect*) AND NOT TITLE-ABS-KEY (clinician*). The database searches were also limited to the following subject areas: business, management and accounting, operations research management, economics and public administration. This limitation was considered necessary because our specific interest was in the approach to the theme in management research. However, we acknowledge the wide discussions on health informatics and clinical decision-making in journals dedicated to these subjects. A further criterion was that studies included had been peer-reviewed and conducted using quantitative or qualitative methods.

Due to discrepancies between user interfaces, the search terms and search strategy were modified slightly to be compatible with the databases. However, the scope of the study remained the same throughout this process. Only articles published in English between 
2010 and 2020 were included in the study. This restriction was imposed due to the recent progress in KM research, notably in the past 10 years in its application to the management of health and social care.

\subsection{Search outcome and exclusion criteria}

The database search yielded a total of 209 articles (Figure 1) for further review, which was conducted based on title, abstract and keyword combinations. The first author (TH) conducted the searches, selected the articles for the study, and evaluated their suitability. The titles, abstracts and keyword screening were used to eliminate studies not meeting the inclusion criteria. At the initial screening stage, we also did a keyword search in Google Scholar and included three additional articles on the bases of the titles of the studies. However, two of these were subsequently excluded because they did not discuss KM in health and social care but KM in the public sector. After the screening phase, we reviewed 39 full texts to determine whether the article answered the research questions and met the inclusion criteria. In the eligibility phase, 27 articles did not meet the inclusion criteria. Out of these, 21 were excluded because they did not study or report the effects of KM. Three more articles were excluded because the context of the study was not the management of health and social care, and a further three because they were either not peer-reviewed or the study design was not consistent with qualitative or quantitative methods.

\subsection{Quality assessment}

The quality of the studies was assessed using a method presented in Gifford et al. (2007). The quality criteria included six items for quantitative studies and 11 items for qualitative studies. Each item was scored on a scale from two to zero (excellent $=2$, some limitations $=$ 1 , several limitations $=0$ ). A quantitative study was excluded if it scored less than five points

\section{Figure 1 PRISMA flow chart (Moher et al., 2009)}

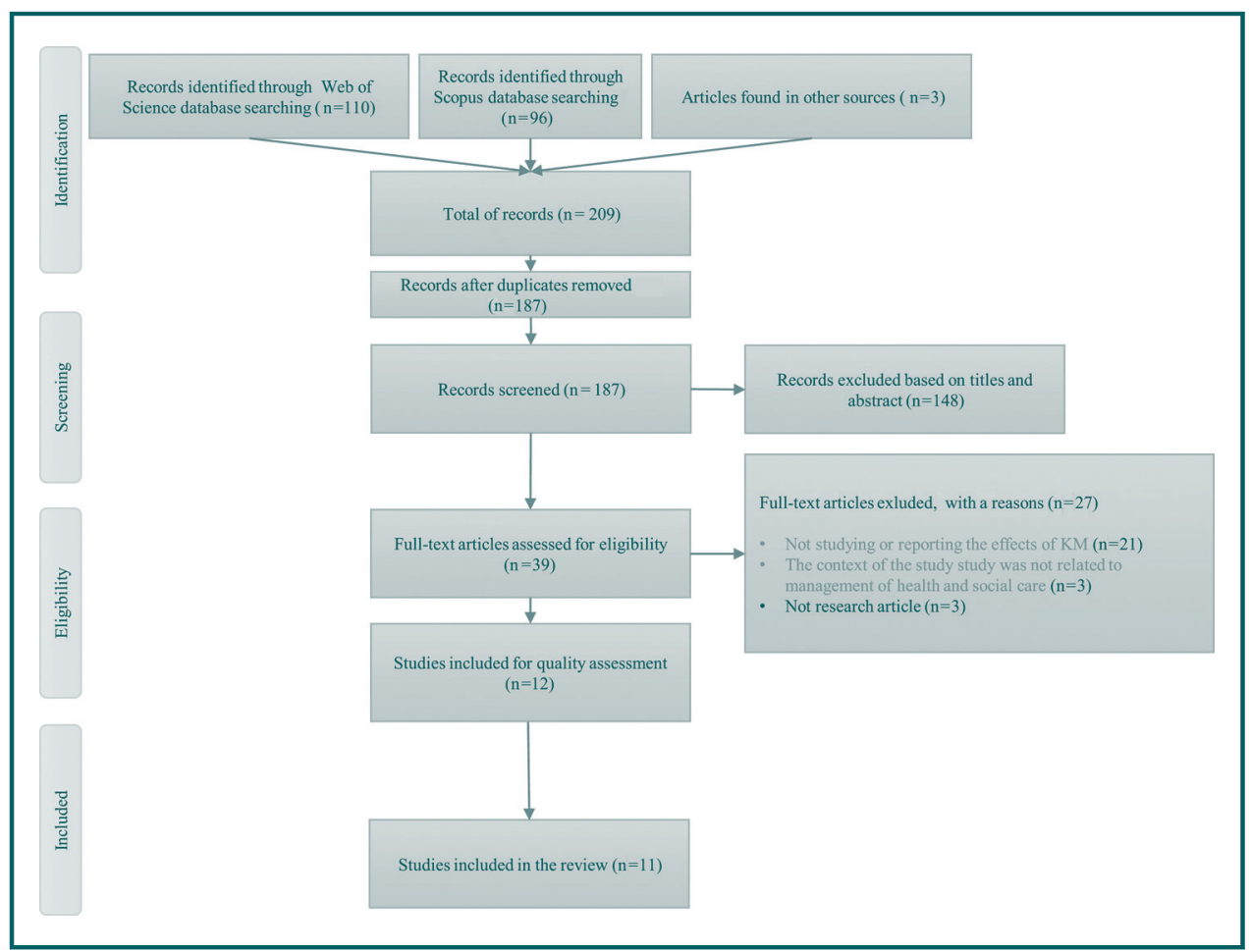


and a qualitative study was excluded if it scored less than nine points. The first author (TH) evaluated all studies. Detailed information about the criteria and the quality assessment of the studies is presented in Appendix (Table A1). One article was excluded from the quality assessment.

\subsection{Data analysis}

A total of 11 studies were included in the review. These studies are summarized in Table 1 by author, year of publication, country of origin, research design and method, sample size, study context, expected or perceived outcomes of $\mathrm{KM}$ and the results of a quality assessment conducted according to Gifford et al. (2007). We applied content analysis to examine the articles. Hence, the key themes of the research emerged from the data and were not guided by any single theory. The content analysis progressed from individual observations to larger entities (Elo et al., 2014). To answer the research questions, the articles were first read once to obtain an overall idea of how the effects of KM were described in the articles. After several readings of the material, instead of individual observations, preliminary themes began to emerge. After data clustering and thematization, the main themes and sub-themes were identified.

\section{Results}

\subsection{Characteristics of the studies included}

According to a geographical breakdown, no continent was ahead of any other. The number of studies by continent was distributed as follows: Europe, four studies (Simonen et al., 2011; De Angelis, 2013; Laihonen and Sillanpää, 2014; Ikonen, 2020), Asia, four studies (Hamidi et al., 2016; Najmi et al., 2017; Tamanna and Sharma, 2019; Ganguly et al., 2020), North America, two studies Sibbald et al. (2016), Parast and Golmohammadi (2019) and Australasia, one study (Massingham et al., 2018). It is also interesting to note that no study offered a perspective on the international context. This lack of international research could be explained by the diversity of national health and social care service systems. For example, the articles reviewed reflected the differences between the social and health-care systems in the United States (USA) and Finland. In the US health-care model, cost containment and quality improvement are the cornerstones of the health-care system (Parast and Golmohammadi, 2019), whereas in Europe, especially in the Nordic countries, the health-care system is built on a strong public service system and societal values (Ikonen, 2020). These differences may have interesting implications for the aims and role of KM, which have not been very thoroughly discussed in the KM literature (Kim et al., 2011; Laihonen and Kokko, 2020).

In our view, the small number of studies $(n=11)$ does not necessarily reflect a lack of interest among the academic community in the impacts of KM but may tell more about the challenging nature of the phenomenon. The impacts of $\mathrm{KM}$ are diverse and often difficult to map (Heisig, 2016). The task becomes even more complicated in the context of the management of health and social care, where the impacts are produced in collaboration between different actors and are decidedly intangible in nature. For example, value-based health care, a recent megatrend in the health-care literature, simultaneously pursues three goals: improving the experience of care, the health of populations and reducing the costs of care (Berwick et al., 2008; Nuno-Solinis, 2019), and this has direct implications for management information and $\mathrm{KM}$. Further, the number of studies was also reduced by our special focus on the management and administrative perspectives, resulting in the exclusion of many studies focusing, for example, on health informatics and IT.

Another significant characteristic of the literature reviewed relates to the research settings. Eight studies reported health care research, and only one was conducted in the social care context (Massingham et al., 2018). In addition, in two studies the research context 
Table 1 Overview of the studies included

\begin{tabular}{lll}
$\begin{array}{l}\text { Author/year/ } \\
\text { country }\end{array}$ & Aim & $\begin{array}{l}\text { Research design } \\
\text { and method }\end{array}$ \\
\hline $\begin{array}{l}\text { Ikonen/2020/ } \\
\text { Finland }\end{array}$ & $\begin{array}{l}\text { What is expected of } \\
\text { knowledge management } \\
\text { in multifactorial social and } \\
\text { health care reform? }\end{array}$ & $\begin{array}{l}\text { Qualitative case } \\
\text { study. Theory- } \\
\text { related analysis }\end{array}$ \\
\hline
\end{tabular}

Ganguly et al./ 2020/India

Evaluate the role of social capital and knowledge sharing in achieving innovation capability of an organization Examine the effects of

Parast and Golmoham associated with the Baldrige model on quality results in the health-care industry using the Baldrige data

Tamanna and

Evaluate the impact of knowledge management and organizational learning on the performance of selected health-care organizations

Descriptive quantitative study. SEM analysis

Sharma/202 India

Designing implementation for KM et al./2018/ Australia 2017/Indonesia

Examine and assess the effect of knowledge management and strategic leadership on the performance of hospitals using variables mediating effect of dynamic capability

Hamidi et al./ Reveal the status of KM in 2016/Iran case study organizations using Bukowitz and William's mode
Questionnaire review, six

hypothesis and PLScontrol variable survey. In depth-
Sample size and study context

22 thematic interviews with national leaders and both politicians and leading civil servants from five different regions

97 senior executives from pharmaceutical organizations (52.15\%

response rate)

rense

ran

Expected or perceived
outcomes of KM

Quality assessment

Quality of knowledge in Excellent

knowledge management, expectations of better

performance, customers need knowledge, KM answers the holistic situation, common understanding (dialogue)

Descriptive questionnaire survey. SPSS analysis, Cronbach alpha value 0.964

Managers, division leaders and health-care professionals $(n=420)$ from 36 hospitals and 10 pharmaceutical sectors (response rate $84 \%$ )

Qualitative study. Roundtable and Action research brainstorming with case (AR), expert-leading study organization collective methods. professionals and leaders Total 18 months (not-for-profit social service organization)

Questionnaire survey. Structural equation modeling (SEM), and Sobel tests

Questionnaire survey. Descriptiveanalytical study using SPSS analytics, regression equation

Survey in four hospitals leaders' $(n=100)$

Survey of managers and 206 for health-care organizations

investments in their information systems and knowledge management KM positive effects on performance and quality of care, $\mathrm{KM}$ will change the hospital, health professionals and patients' interactions. It will also impact continuity of care

Expectations of KM could Some limits affect social responsibility,

competitive advantage cultural change,

performance, cost reduction and risk management

Knowledge management on the performance of hospitals indicated that the higher the knowledge management, the higher the hospital performance if the mediated dynamic capability was also higher Managers to use knowledge management guide in successful performance and apply a knowledge management system in the health sector to enhance performance with an emphasis on effectiveness and provide

\section{Some limits}

Some limits

Some limits Knowledge quality has a crucial effect on innovation capabilities; managers could think of deploying better knowledge management platforms or knowledge quality management programs to ensure the availability of high-quality knowledge

The sample for this study Quality-driven healthconsists of all health-care care organizations, organizations that applied leaders recognized the for the Baldrige award critical role of KM. Healthbetween 1999 and 2006. care organizations need In total, 161 observations to make proper

Some limits

Excellent 


\section{Table 1}

Author/year/

country
Aim

Research design

Sample size and study context

and method

Expected or perceived outcomes of KM

Quality

assessment

recommendations to

develop the software and implementation of

knowledge to improve

decision-making at

university level and

customer satisfaction
Qualitative study.

Case study approach, in-depth care context with a specific focus on understanding how senior types of knowledge and knowledge processes in decision-making
Qualitative study. Two-step data collection with a approach

Qualitative analysis on processes meta-analytical

Interviews with $\mathrm{HC}$ managers $(n=24)$, other sources were public documents (strategy, etc.)

Semi-structured data collection about service usage services interviews and pre-post leaders use different plan of KM-OI in public administrations worldwide

Simonen et al. Map managers understanding of effectiveness and assess the application of knowledge of effectiveness in secondary health-care management servants in Brazil and Germany ministries (response rate: $84,14 \%$ )

Questionnaire (measurement model) and PLS

\section{(structural model)} Qualitative study. Inductive content analysis

Interviews with healthcare managers in context of hospital $(n=38)$
In discussing KM,

leaders acknowledged

the importance of transferring knowledge among people, but more often understood KM as encompassing performance measurement, information management and human resources strategies

The paper identified knowledge-related problems in system-level measurement and concluded that significant advances are needed in public knowledge management before the effectiveness of services can be evaluated in a meaningful way

$\mathrm{KM}$ plays a role in the policy-making process, but it alone does not se expectations

Excellent

Some limits

The presence of

effectiveness in

departments was still quite rare, especially in applying knowledge of costeffectiveness. All the secondary health care managers and department directors followed a strategy of larger assessment of matters within an organization, which is part of knowledge management. In knowledge management, the use of knowledge is tied to the strategic management and decision-making of an organization

Notes: PLS = Partial least squares; CFA = confirmatory factor analysis; OI = organizational intelligence; SPSS = statistical package for the social sciences; $\mathrm{HC}=$ healthcare 
comprised integrated health and social care (Ikonen, 2020; Laihonen and Sillanpää, 2014). The paucity of KM research in the management of social services or social care raises the question how researchers in different parts of the world perceive and define social services. Often, these are taken to be publicly produced services or benefits that a given population enjoys. This public and not-for-profit orientation may be one reason for a lack of interest on the part of KM researchers; the public sector has not been an attractive environment Massaro et al. (2015) despite the importance of the sector and the potential of KM to improve the management of such services (Laihonen and Mäntylä, 2018). The management of health care, which has attracted more attention from KM researchers than the management of social care, is globally divided into both public Ikonen (2020) and private service production (Parast and Golmohammadi, 2019). Indeed, health care is a huge global business, which makes it more interesting for $\mathrm{KM}$ as an approach originating from the knowledge-based view of a firm and focusing on the creation of sustainable competitive advantage (Grant, 1996; Spender, 1996).

A final issue we want to highlight here concerns the question of how the context of the research affects the research design. Although the small number of studies inhibits generalization, it seems that the qualitative approach predominates in the complex contexts of managing social and integrated care while the quantitative approach is preferred in settings where data are either already available or can be easily gathered by applying a survey method. This methodological question also emerged in the geographical review. All studies on the Asian continent used quantitative methods while studies in Europe, North America and Australasia used qualitative methods (Table 2). Overall, five studies were qualitative and six studies applied a quantitative approach. Earlier, Inkinen (2016) noted the

Table 2 Six main categories among the effects of KM on the management of health and social care

\begin{tabular}{|c|c|c|}
\hline Category & Effects of KM on the management of health and social care & Reference (e.g.) \\
\hline \multirow[t]{2}{*}{$\begin{array}{l}\text { Enhanced understanding } \\
\text { of customer needs }\end{array}$} & $\begin{array}{l}\text { KM increases health and social care organizations' } \\
\text { understanding of citizens' service needs }\end{array}$ & (Ikonen, 2020; Massingham et al., 2018) \\
\hline & $\begin{array}{l}\text { KM strategy develops health organizations' understanding } \\
\text { of complex phenomena by increasing awareness of the } \\
\text { changes in the operating environment }\end{array}$ & $\begin{array}{l}\text { (Tamanna and Sharma, 2019; Simonen } \\
\text { et al., 2011) }\end{array}$ \\
\hline \multirow[t]{2}{*}{$\begin{array}{l}\text { Improved organizational } \\
\text { performance }\end{array}$} & $\begin{array}{l}\text { KM supports cost control by identifying and capturing best } \\
\text { practices and improving efficiency, reducing medical errors } \\
\text { and reducing waste in routine tasks }\end{array}$ & $\begin{array}{l}\text { (Tamanna and Sharma, 2019; } \\
\text { Massingham et al., 2018) }\end{array}$ \\
\hline & $\begin{array}{l}\text { The impact of KM on organizational performance was } \\
\text { observed through the mediating variable of dynamic } \\
\text { capability }\end{array}$ & (Najmi et al., 2017) \\
\hline \multirow[t]{2}{*}{$\begin{array}{l}\text { Better targeted decision- } \\
\text { making }\end{array}$} & $\begin{array}{l}\mathrm{KM} \text { improves decision-making by providing faster and more } \\
\text { accurate decision-making support }\end{array}$ & $\begin{array}{l}\text { (lkonen, 2020; Hamidi et al., 2016; } \\
\text { Simonen et al., 2011; Massingham et al., } \\
\text { 2018) }\end{array}$ \\
\hline & $\begin{array}{l}\text { KM promotes strategic planning with a continuous loop of } \\
\text { knowledge sharing }\end{array}$ & (Sibbald et al., 2016; De Angelis, 2013) \\
\hline \multirow[t]{2}{*}{$\begin{array}{l}\text { Improved quality of } \\
\text { services }\end{array}$} & $\begin{array}{l}\text { KM improves the quality of services through advanced } \\
\text { knowledge sharing }\end{array}$ & (Ganguly et al., 2020) \\
\hline & $\begin{array}{l}\text { KM improves patient safety by increasing an organization's } \\
\text { innovation capabilities and reliability of information and } \\
\text { knowledge }\end{array}$ & $\begin{array}{l}\text { (Ikonen, 2020; Parast and } \\
\text { Golmohammadi, 2019) }\end{array}$ \\
\hline \multirow[t]{2}{*}{$\begin{array}{l}\text { Behavioral or cultural } \\
\text { change }\end{array}$} & KM drives individual and organizational learning & $\begin{array}{l}\text { (Tamanna and Sharma, 2019; } \\
\text { Massingham et al., 2018; Sibbald et al., } \\
\text { 2016) }\end{array}$ \\
\hline & $\begin{array}{l}\text { KM improves motivation, morale, commitment and positive } \\
\text { work behavior by resolving tensions between employee } \\
\text { empowerment and client care }\end{array}$ & (Massingham et al., 2018) \\
\hline $\begin{array}{l}\text { Improved risk } \\
\text { management }\end{array}$ & $\begin{array}{l}\text { KM brings objectivity and clarity to risk management by } \\
\text { addressing the complexity of risks in the organization }\end{array}$ & (Massingham et al., 2018) \\
\hline
\end{tabular}


predominance of survey strategy and statistical methods and called for more case studies. Similarly, Heisig et al. (2016) recognized the need for causal research designs scrutinizing the effects of KM. Structural equation modeling (SEM) or combinations thereof (e.g. PLSSEM) were the most popular methods used in quantitative studies. In the qualitative studies, the case study approach with content analysis was the most used approach. SEM analyses typically involve large data sets. In KM studies, a SEM analysis is typically applied to explain the relationships between latent and observable variables, whereas qualitative content analysis is applied to understand the mechanisms and processes leading to the perceived effects. It is noteworthy that no study applied a mixed methods approach. By applying methodological triangulation, KM research could gain added value in examining the phenomena under study.

\subsection{Effects of knowledge management on the management of health and social care}

Because the origins of KM research are in knowledge-based views of the firm Grant (1996), Spender (1996) and in improving organizational performance (Kalling, 2003), it was expected that these same objectives would be pursued in the context of managing health and social care. In our review, we identified six main categories among the effects of KM on the management of health and social care:

1. Enhanced understanding of customer needs;

2. Improved organizational performance;

3. Better targeted decision-making;

4. Improved quality of service;

5. Behavioral or cultural change; and

6. Improved risk management. These categories are summarized in Table 2.

Notably, there were two distinct approaches to discussing the effects: the studies referred either to the effects of KM pursued in general terms or to the effects realized as a result of specific KM initiatives. As an outcome of KM pursued, "enhanced understanding of customer needs" was discussed in various ways. A thorough understanding of the needs of customers was considered a starting point in value creation (Massingham et al., 2018; Ikonen, 2020). In the case of private health and social care, the focus was on business performance (Massingham et al., 2018; Tamanna and Sharma, 2019), whereas in the public sector, the discussion was focused on the availability and appropriate use of publicly funded services (Ikonen, 2020). In the latter case, the objective and value of KM were seen in supporting the provision of high-quality health and social care services, and thus in improving the overall welfare of the population.

The outcome category realized, "improved organizational performance", highlighted the pivotal role and importance of performance measurement and performance indicators Simonen et al. (2011), De Angelis (2013), Hamidi et al. (2016) in cost control (Najmi et al., 2017; Tamanna and Sharma, 2019). The literature focused not only on the role of KM in the performance management of individual health and social care organizations but also on its role in assessing the effectiveness of the service system more widely (Laihonen and Sillanpää, 2014; Ikonen, 2020). Indeed, KM was considered to help in identifying important resources, reforming processes, applying new managerial tools and improving customer satisfaction (Hamidi et al., 2016). Finally, Laihonen and Sillanpää (2014) showed how a certain maturity was required by both organizational KM and system-level enablers and interfaces before the effectiveness of health and social care services could be measured. For example, according to these authors, siloed information systems and lack of capabilities 
in information production and use may significantly impair the capacity to gather, analyze and make use of performance information.

In the "better targeted decision-making" category, both effects pursued Ikonen (2020), Hamidi et al. (2016), Simonen et al. (2011) and effects realized Hamidi et al. (2016) were reported. The developmental effects of KM on decision-making were seen in particular in that these provide more accurate information for decision-making in a more up-to-date way (Simonen et al., 2011; Hamidi et al., 2016; Ikonen, 2020). In addition, from the strategic planning perspective, $\mathrm{KM}$ promoted continuous knowledge sharing, which provided more support for planning (De Angelis, 2013; Sibbald et al., 2016).

The category "improved quality of service" referred not only to the quality of services (Parast and Golmohammadi, 2019; Ikonen, 2020; Ganguly et al., 2020) but also to another aspect of quality: the quality and reliability of information and knowledge (Parast and Golmohammadi, 2019). The task and effects of KM were intended to enhance the abilities of organizations to innovate, which was expected to improve the quality of services (Ganguly et al., 2020). Ideally, the processes of creating, storing, transferring and applying knowledge Alavi and Leidner (2001) can make the right information available to an organization at the right time and in the right form, thus making it easier for an organization to achieve a specific goal Parast and Golmohammadi (2019) or to support policymakers in reforming the service system (Ikonen, 2020).

In the two last categories, KM was also expected to support "behavioral or cultural change" Sibbald et al. (2016), Massingham et al. (2018), Tamanna and Sharma (2019) and "improved risk management" (Massingham et al., 2018). These effects have been widely discussed and anticipated in the KM literature (Corfield and Paton, 2016; Ilvonen et al., 2015; Rodriguez and Edwards, 2014). However, it seems that they have not been as carefully analyzed or evaluated in the context of health and social care management, even though Williams (2012), for example, considers KM and learning integral to the integration of health and social care. Regarding cultural change, KM was considered more as a mechanism for changing work culture and ways of working, thereby supporting both individual Massingham et al. (2018) and organizational learning (Sibbald et al., 2016; Massingham et al., 2018; Tamanna and Sharma, 2019). Moreover, KM was expected to have a positive effect on work behaviors such as teamwork and collaboration (Massingham et al., 2018). The complexity of risk management, especially in social services, leads organizations to require the management model to cover not only traditional risk management but also factors related to the nature of information, such as tacit information (Massingham et al., 2018). The role of KM in managing the risks in the complex environment was found to be related to improving the objectivity of information and cognitive clarity both during the risk event and in risk prevention (Massingham et al., 2018).

\section{Discussion}

The aim of the study was to review the existing evidence on the effects of KM on the management of health and social care and to propose a preliminary framework based on the review for evaluating the effects of KM to support both academics and practitioners in further developing $\mathrm{KM}$ and increasing its relevance in the management of health and social care. In this section, we will discuss the three main themes raised by the review and formulate our proposal for a preliminary evaluation framework. To help KM researchers in their endeavor to advance our knowledge and understanding of how to maximize the benefit of KM in the management of health and social care, nine research propositions are offered, based on the following three themes: conceptual and theoretical development, focus of KM implementation and diversity of research settings.

First, the review revealed the paucity of research regarding the effects of $\mathrm{KM}$ on the management of health and social care. As shown in the previous section, only a few studies have reported verified effects of KM in the given context Simonen et al. (2011), De Angelis (2013), 
Hamidi et al. (2016), Najmi et al. (2017), Tamanna and Sharma (2019) and only one study focused on social care (Massingham et al., 2018). From the practical viewpoint, this small amount of evidence on the effects of KM can be considered a major gap when seeking justification for KM investments or trying to choose the most effective approaches to be applied. A lack of empirical evidence regarding the effects of KM has been reported previously, for example, by Heisig et al. (2016) and Inkinen (2016) but this is the first systematic review to be targeted at the specific context of the management of health and social care. Table 2 summarized the variety of anticipated effects related to a better understanding of customer needs (Massingham et al., 2018), performance improvement (Tamanna and Sharma, 2019), decision-making (Ikonen, 2020; Hamidi et al., 2016; Simonen et al., 2011), quality improvement (Ganguly et al., 2020), cultural change (Sibbald et al., 2016) and risk management (Massingham et al., 2018). The realized and verified effects of KM appeared to be even more limited but relate to the same main categories as the anticipated effects. Clearly, these outcomes differ from the findings of Inkinen's (2016) review, where firm performance was typically operationalized as profitability, speed to market or market share. Indeed, it is critical for KM how the organizations' objectives are defined (e.g. efficiency and costs vs quality of life and citizens' well-being) because it is these which will define what knowledge is prioritized in decision-making.

Our results complement the findings of earlier reviews carried out in the business context and highlight the special nature of the management of health and social care as regard managerial knowledge needs and KM. The results show that the context creates a need for multi-level evaluation of the effects and the literature reviewed provides a starting point for developing a holistic evaluation framework. This framework should consider the perspectives of individual health care professionals, the safety and quality of services and the organizational objectives related to performance improvement, risk management and cultural change. In addition, the articles reviewed revealed the need to evaluate the value of $\mathrm{KM}$ initiatives for inter-organizational collaboration and in gaining a system-wide perspective in strategic planning and the creation of customer value. Indeed, customers' role and knowledge are important components of value co-creation and $\mathrm{KM}$ is a mediating factor in this process (Caputo et al., 2019). Moreover, the distinct logics of financial management and well-being Laihonen and Kokko (2020) are omnipresent in this context and KM should provide decision-makers with balanced information for use in planning and implementing not only the most effective KM initiatives but also, more importantly, efficient and effective services in health and social care (Ikonen, 2020; Laihonen and Sillanpää, 2014). Finally, the review evidenced a need for KM research to move from listing the expectations to determining the realized and verified effects of various KM initiatives.

To summarize the discussion, Figure 2 presents a preliminary framework for categorizing the effects of $\mathrm{KM}$ on the management of health and social care. Although various maturity and evaluation models of KM are available, in most cases, their primary focus has been on the processes of creating, acquiring, storing and transferring information (Liebowitz et al., 2000; Gold et al., 2001; Jääskeläinen et al., 2020), not on the actual application of knowledge and the effects of KM.

The framework provides a tool for use in identifying and evaluating the effects of KM at various levels in the management of health and social care. The framework takes a managerial view and acknowledges that organizations need to cope with diminishing financial resources and increasing needs for services. The "sweet spot" is always a compromise between financial sustainability and welfare outcomes, which calls for managerial judgment (Spender, 2014). Therefore, decision-makers must address the following difficult questions when planning any KM investments or initiatives: At what point can KM generate welfare benefits? When will an increase in investments cease to provide added value in terms of health outcomes? The multi-level framework proposed highlights the richness of KM approaches supporting knowledge-intensive value creation. It shows 
Figure 2 Preliminary framework for categorizing the effects of KM on the management of health and social care

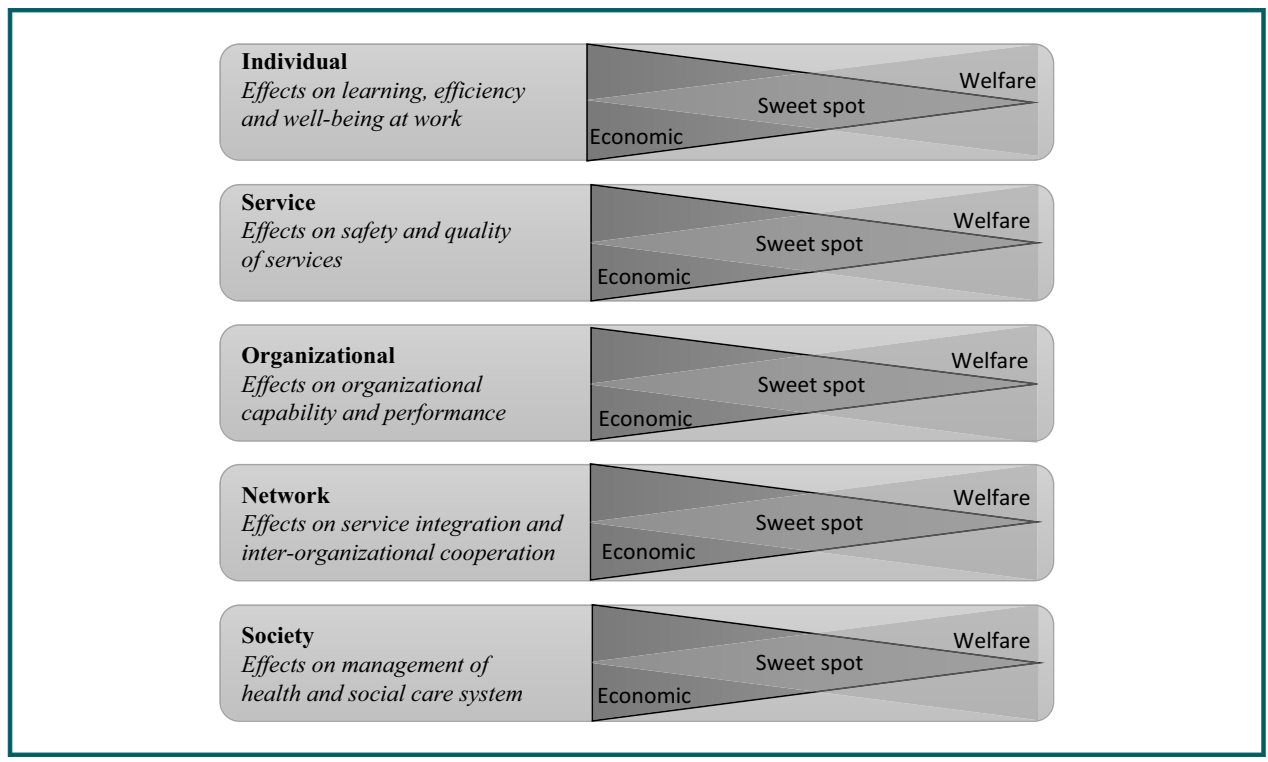

how the effects of KM on the management of health and social care are not only perceived as improved decision-making but also are more versatile. At the individual level, KM initiatives typically aim at improving the productivity of knowledge workers, and well-being at work has also been increasingly discussed together with the efficiency of work. Indeed, job satisfaction, work motivation, commitment to work and employee turnover are concrete outcome measures typically used at this level to complement the productivity viewpoint. At the process level, efficiency measures are complemented with data on quality of care, like patient safety. At the organizational level, objectives such as overall costs of care, regulatory compliance, customer service and many other organizational objectives come into play. The latter two levels have raised most interest in the KM literature, as our review showed. Nevertheless, the management of health and social care also needs to be concerned about network and societal level effects. Service integration, inter-organizational knowledge flow and multi-professional and multi-sectoral collaboration are critical elements of an effective health and social care. Therefore, KM initiatives need to support these, and it is important to develop methods and tools for evaluating the success of KM in these areas. Ultimately, the success of the whole service system will be measured in terms of its ability to provide cost effective services for citizens, that is, its societal impact.

Second, inspired by Dumay (2020), a further observation was that in many cases, also in the management of health and social care, KM aims to solve "tame" organizational problems. By this Dumay means that instead of wicked social problems, like health or social problems, KM aims to improve organizational efficiency by managing knowledge within the organization. However, in our review some studies expressed an interest in system-level analysis and solving challenges at the level of society. These considerations take the analyst back to the origins of the knowledge-based view and KM; the aim is to comprehend the nature of an organization and to improve its overall performance (Hansen et al., 1999; Laihonen and Mäntylä, 2018; Ferreira et al., 2020). In the management of health and social care, this means that the objectives of promoting the welfare and societal well-being should always be the starting point when determining a knowledge strategy. This connects to the interest in new (innovative) concepts of care, as well as in tools and models that are aligned with value-based, integrated health care (Colldén and Hellström, 2018). These ideas have 
shifted the focus from volume to value (Berwick et al., 2008; Porter et al., 2016), and challenged not only performance measurement and management but also KM in the specific context of managing health and social care. New objectives re-define the requirements for organizational and system design, and also articulate new needs for decision-making information. Our review shows that there is still work to be done to move beyond tame organizational problems. The big challenge for KM research and practice in the management of health and social care can be formulated as: How can KM help in solving societal problems and supporting health and social managers in planning, designing and implementing sustainable health and social care?

In addition to the definition of $\mathrm{KM}$, another important question to be considered when discussing the effects of $\mathrm{KM}$ relates to the operationalization of the definition; what procedures, initiatives or practices are applied as KM. Inkinen (2016) followed Heisig (2009) and considered KM practices under four categories: human-oriented factors, organization-oriented factors, technology-oriented factors and management processesoriented factors. Nicolini et al. (2008) in their review categorized KM initiatives in health care into IT-based, socially-based and human-resource driven. Indeed, there are differences in how KM is operationalized in the management of health and social care. The management perspective has not been highlighted in this context, which was one starting point for this article. Another major difference from Inkinen's (2016) results relates to the modest appearance of "innovation" in our review. The emphasis in the KM literature on the management of health and social care has been more on the exploitation of the existing knowledge and evidence than on exploring innovative concepts and methods (Gastaldi et al., 2018).

Third, the review raised some methodological issues. As noted earlier in this article, there is a clear division between the quantitative research conducted mainly in Asia and the qualitative methods applied in Europe. The same observation has been highlighted earlier by Heisig et al. (2016) and Inkinen (2016), who have called for more qualitative research to better understand the causal relations between KM and performance outcomes. The quantitative approaches need to be complemented with qualitative research acknowledging the ambiguity of the knowledge processes and prioritizing actors' sensemaking processes over data (Hess and Adams, 2002; Spender, 2014). Both methodological approaches have their respective acknowledged strengths and weaknesses, and there is an urgent need for studies applying multiple methods. An attempt should also be made to better understand methodological differences regarding the diversity of social situations. Only then could we understand the various effects of different strategies, structures and practices of KM applied in the management of health and social care.

Table 3 summarizes the discussion and presents nine research propositions to help KM researchers in their endeavors to advance our knowledge and understanding of the effects of $\mathrm{KM}$ on the management of health and social care.

\section{Conclusions}

This study makes two contributions to the literature. First, it pinpoints the lamentable research gap regarding the effects of $\mathrm{KM}$ on the management of health and social care. The results of our literature review indicate that the current understanding of these effects is both meager and fragmentary. The results also demonstrated that the focus of KM research in the management of health and social care has been on tame organizational problems while wicked societal problems have been mostly ignored. Furthermore, earlier research has identified several anticipated and expected effects of KM, but less is known about its realized and verified effects. The implications of these findings for KM research are clear: more research needs to be dedicated to studying the real effects of $\mathrm{KM}$ at different levels of health and social care management. Also, from the practical viewpoint, practitioners would 
- Proposition 1: There is a need for both theoretical and empirical research regarding the effects of $\mathrm{KM}$ on the management of health and social care

- Proposition 2: Research on the effects of $\mathrm{KM}$ has focused extensively on health care, so there is a need to focus more on social care and KM's potential to support service integration

- Proposition 3: Frameworks for approaching and categorizing the effects of $\mathrm{KM}$ are mostly developed in other sectors than health and social care and there is a need to develop and test theoretically sound and practically feasible impact indicators to measure the benefits of $\mathrm{KM}$ in health and social care
- Proposition 4: Objectives of KM differ between the levels of analysis, and therefore, the effects of $\mathrm{KM}$ also need to be studied at multiple levels of management - Proposition 5: Focus of KM research in health and social care has been primarily on the effects on internal efficiency, this view needs to be complemented with settings studying the effects of $\mathrm{KM}$ on interorganizational collaboration and the system level outcomes

- Proposition 6: Exploitation of the existing knowledge and evidence has dominated the $\mathrm{KM}$ discussion; there is a need to better understand the role and effects of $\mathrm{KM}$ in mastering organizational ambidexterity in health and social care
- Proposition 7: Quantitative research designs dominate the literature; more qualitative research is needed to better understand the causal relations between $\mathrm{KM}$ and performance outcomes

- Proposition 8: Multi-method approaches are needed to better understand the various effects of different strategies, structures and practices of $\mathrm{KM}$ applied in the management of health and social care

- Proposition 9: Comparative research settings are needed to recognize and transfer the most effective KM practices

require more information about the realized benefits to justify their investment in KM. Second, the article constructed a preliminary framework for evaluating the effects of KM on the management of health and social care. Despite the weaknesses identified in the literature, it provided a starting point for developing the proposed framework. Considering the importance of health and social care services, it must be in the interests of future KM research to extend its contributions from individual indicators and organizational decisionmaking support to building sustainable and fair health and social care systems. However, this entails the development of research settings and designs that provide information about the real benefits of $\mathrm{KM}$ in promoting health and well-being not only within organizations but also across organizational boundaries and in society in general. These aims also necessitate the application of novel methodological approaches combining the strengths of qualitative and quantitative methods.

The issue of $\mathrm{KM}$ in the management of health and social care offers several avenues for future research. In continuing the agenda of the present study, one important research area is the evaluation of the real and verified effects of $\mathrm{KM}$ at different levels of the management of health and social care. Both theoretical and practical contributions in this area are urgently needed. We need more information about the effects of the various strategies, structures and practices of KM. Furthermore, the viewpoint of a patient or a service user needs to be further highlighted in evaluating the effects of $\mathrm{KM}$. The main limitation of the present study is that only a small number of articles were reviewed. This limitation can be partly explained by our inclusion and exclusion criteria. It is noteworthy that the effects of KM may be implicitly included in the research setting and not explicitly highlighted, and therefore, we may have missed some relevant studies from the viewpoint of our research question. However, the purpose of the literature review was not to provide definitive answers but to identify research gaps and propose avenues for future research. Hence, the present study has succeeded despite its limitations. A major implication of this study is that in future studies it is worth making the effects of KM more explicit.

\section{References}

Alavi, M. and Leidner, D. (2001), "Review: knowledge management and knowledge management systems. Conceptual foundations and research issues", MIS Quarterly, Vol. 25 No. 1, pp. 107-136. 
Andreeva, T. and Kianto, A. (2012), "Does knowledge management really matter? Linking KM practices, competitiveness and economic performance", Journal of Knowledge Management, Vol. 16 No. 4, pp. 617-636.

Antonacci, G., Fronzetti Colladon, A., Stefanini, A. and Gloor, P. (2017), "It is rotating leaders who build the swarm: social network determinants of growth for healthcare virtual communities of practice", Journal of Knowledge Management, Vol. 21 No. 5, pp. 1218-1239.

Arefin, M.S., Hoque, M.R. and Rasul, T. (2020), "Organizational learning culture and business intelligence systems of health-care organizations in an emerging economy", Journal of Knowledge Management, Vol. 25 No. 3, pp. 573-594.

Ayatollahi, H. and Zeraatkar, K. (2020), "Factors influencing the success of knowledge management process in health care organisations: a literature review", Health Information \& Libraries Journal, Vol. 37 No. 2, pp. 98-117.

Berwick, D.M., Nolan, T.W. and Whittington, J. (2008), "The triple aim: care, health and costs: the remaining barriers to integrated care are not technical; they are political", Health Affairs, Vol. 27 No. 3, pp. 759-769.

Boder, A. (2006), "Collective intelligence: a keystone in knowledge management", Journal of Knowledge Management, Vol. 10 No. 1, pp. 81-93.

Caputo, F., Garcia-Perez, A., Cillo, V. and Giacosa, E. (2019), "A knowledge-based view of people and technology: directions for a value co-creation-based learning organization", Journal of Knowledge Management, Vol. 23 No. 7, pp. 1314-1334.

Colldén, C. and Hellström, A. (2018), "Value-based healthcare translated: a complementary view of implementation", BMC Health Services Research, Vol. 18 No. 1, pp. 681-692.

Corfield, A. and Paton, R. (2016), "Investigating knowledge management: can KM really change organizational culture", Journal of Knowledge Management, Vol. 20 No. 1, pp. 88-103.

Corso, M., Martini, A., Paolucci, E. and Pellegrini, L. (2001), "Knowledge management in product innovation: an interpretative review", International Journal of Management Reviews, Vol. 3 No. 4, pp. 341-352.

Currie, G., Waring, J. and Finn, R. (2008), "The limits of knowledge management for UK public services modernization: the case of patient safety and service quality”, Public Administration, Vol. 86 No. 2, pp. 363-385.

De Angelis, C. (2013), "A knowledge management and organizational intelligence model for public administration", International Journal of Public Administration, Vol. 36 No. 11, pp. 807-819.

Du Plessis, M. (2007), "The role of knowledge management in innovation", Journal of Knowledge Management, Vol. 11 No. 4, pp. 20-29.

Dumay, J. (2020), "Using critical KM to address wicked problems", Knowledge Management Research \& Practice, Vol. ahead-of-print No. ahead-of-print, pp. 1-9, doi: 10.1080/14778238.2020.1790310.

Elo, S., Kääriäinen, M., Kanste, O., Pölkki, T., Utriainen, K. and Kyngäs, H. (2014), "Qualitative content analysis: a focus on trustworthiness", SAGE Open, Vol. 4 No. 1, pp. 1-10.

Ferreira, J., Mueller, J. and Papa, A. (2020), "Strategic knowledge management: theory, practice and future challenges", Journal of Knowledge Management, Vol. 24 No. 2, pp. 121-126.

Filippini, R., Güttel, W.H. and Nosella, A. (2012), "Ambidexterity and the evolution of knowledge management initiatives", Journal of Business Research, Vol. 65 No. 3, pp. 317-324.

Firestone, J.M. and McElroy, M.W. (2004), "Organizational learning and knowledge management: the relationship", The Learning Organization, Vol. 11 No. 2, pp. 177-184.

Fletcher-Brown, J., Carter, D., Pereira, V. and Chandwani, R. (2020), "Mobile technology to give a resource-based knowledge management advantage to community health nurses in an emerging economies context", Journal of Knowledge Management, Vol. 25 No. 3, pp. 525-544.

Ganguly, A., Talukdar, A. and Chatterjee, D. (2020), "Social capital, knowledge quality, knowledge sharing and innovation capability: an empirical study of the Indian pharmaceutical sector", Knowledge and Process Management, Vol. 27 No. 1, pp. 25-42.

Gastaldi, L., Appio, F.P., Corso, M. and Pistorio, A. (2018), "Managing the exploration-exploitation paradox in healthcare: three complementary paths to leverage on the digital transformation", Business Process Management Journal, Vol. 24 No. 5, pp. 1200-1234. 
Gifford, W., Davies, B., Edwards, N., Griffin, P. and Lybanon, V. (2007), "Managerial leadership for nurses' use of research evidence: an integrative review of the literature", Worldviews on Evidence-Based Nursing, Vol. 4 No. 3, pp. 126-145.

Gold, A., Malhotra, A. and Segars, A. (2001), "Knowledge management: an organizational capabilities perspective", Journal of Management Information Systems, Vol. 18 No. 1, pp. 185-214.

Grant, R.M. (1996), "Toward a knowledge-based theory of the firm", Strategic Management Journal, Vol. 17 No. S2, pp. 109-122.

Gupta, A.K., Smith, K.G. and Shalley, C.E. (2006), "The interplay between exploration and exploitation", Academy of Management Journal, Vol. 49 No. 4, pp. 693-706.

Hamidi, Y., Soltanian, A., Mohammadfam, I. and Rabbani, T. (2016), "Studying the status of knowledge management aspects by using bukowitz and william model in staff and deputy of Hamadan university of medical sciences", Bulletin de la Société Royale Des Sciences de Liège, Vol. 85, pp. 1529-1544.

Hansen, M.T., Nohria, N. and Tierney, T. (1999), "What's your strategy for managing knowledge?", Harvard Business Review, Vol. 77 No. 2, pp. 106-116.

Heisig, P. (2009), "Harmonisation of knowledge management - comparing $160 \mathrm{KM}$ frameworks around the globe", Journal of Knowledge Management, Vol. 13 No. 4, pp. 4-31.

Heisig, P., Suraj, O.A., Kianto, A., Kemboi, C., Perez Arrau, G. and Fathi Easa, N. (2016), "Knowledge management and business performance: global experts' views on future research needs", Journal of Knowledge Management, Vol. 20 No. 6, pp. 1169-1198.

Hess, M. and Adams, D. (2002), "Knowing and skilling in contemporary public administration", Australian Journal of Public Administration, Vol. 61 No. 4, pp. 68-79.

Ikonen, A.K. (2020), "Knowledge as a critical success factor in the Finnish social and health-care reform", Knowledge Management Research \& Practice, Vol. 18 No. 1, pp. 69-80.

Ilvonen, I., Jussila, J. and Kärkkäinen, H. (2015), "Towards a business-driven process for knowledge security risk management: making sense of knowledge risks", International Journal of Knowledge Management, Vol. 11 No. 4, pp. 1-18.

Inkinen, H. (2016), "Review of empirical research on knowledge management practices and firm performance", Journal of Knowledge Management, Vol. 20 No. 2, pp. 230-257.

Jääskeläinen, A., Sillanpää, V., Helander, N., Leskelä, R.L., Haavisto, I., Laasonen, V. and Torkki, P. (2020), "Designing a maturity model for analyzing information and knowledge management in the public sector", VINE Journal of Information and Knowledge Management Systems, Vol. ahead-of-print No. ahead-of-print, doi: 10.1108/VJIKMS-01-2020-0017.

Jamshed, S. and Majeed, N. (2019), "Relationship between team culture and team performance through lens of knowledge sharing and team emotional intelligence", Journal of Knowledge Management, Vol. 23 No. 1, pp. 90-109.

Kalling, T. (2003), "Organization-internal transfer of knowledge and the role of motivation: a qualitative case study", Knowledge and Process Management, Vol. 10 No. 2, pp. 115-126.

Kaur, S., Gupta, S., Singh, S.K. and Perano, M. (2019), "Organizational ambidexterity through global partnerships: a cognitive computing perspective", Technological Forecasting and Social Change, Vol. 145, pp. 43-54.

Kim, Y.M., Newby-Bennett, D. and Song, H.J. (2011), "Knowledge sharing and institutionalism in the healthcare industry", Journal of Knowledge Management, Vol. 16 No. 3, pp. 480-494.

Kogut, B. and Zander, U. (1992), "Knowledge of the firm, combinative capabilities, and the replication of technology", Organization Science, Vol. 3 No. 3, pp. 383-397.

Kothari, A., Hovanec, N., Hastie, R. and Sibbald, S. (2011), "Lessons from the business sector for successful knowledge management in health care: a systematic review", BMC Health Services Research, Vol. 11 No. 1, p. 173.

Laihonen, H. and Huhtamäki, J. (2020), "Organizational hybridity and fluidity: deriving new strategies for dynamic knowledge management", Knowledge Management Research \& Practice, Vol. ahead-of-print No. ahead-of-print, pp. 1-13, doi: 10.1080/14778238.2020.1794993.

Laihonen, H. and Kokko, P. (2020), "Knowledge management and hybridity of institutional logics in the public sector", Knowledge Management Research \& Practice, Vol. ahead-of-print No. ahead-of-print, doi: 10.1080/14778238.2020.1788429. 
Laihonen, H. and Mäntylä, S. (2018), "Strategic knowledge management and evolving local government", Journal of Knowledge Management, Vol. 22 No. 1, pp. 219-234.

Laihonen, H. and Sillanpää, V. (2014), "What is the role of knowledge management in establishing the effectiveness of public welfare services?", Knowledge and Process Management, Vol. 21 No. 2, pp. 112-121.

Liberati, A., Altman, D.G., Tetzlaff, J., Mulrow, C., Gøtzsche, P.C., Ioannidis, J.P.A., Clarke, M., Devereaux, P.J., Kleijnen, J. and Moher, D. (2009), "The PRISMA statement for reporting systematic reviews and meta-analyses of studies that evaluate health care interventions: explanation and elaboration", Annals of Internal Medicine, Vol. 151 No. 4, pp. 65-94.

Liebowitz, J., Rubenstein-Montano, B., McCaw, D., Buchwalter, J., Browning, C., Newman, B. and Rebeck, K. (2000), "The knowledge audit”, Knowledge and Process Management, Vol. 7 No. 1, pp. 3-10.

Lin, S.W. and Lo, L. (2015), "Mechanism to motivate knowledge sharing: integrating the reward system and social networks perspectives", Journal of Knowledge Management, Vol. 19 No. 2, pp. 212-235.

Lunden, A., Teräs, M., Kvist, T. and Häggman-Laitila, A. (2017), "A systematic review of factors influencing knowledge management and the nurse leaders' role", Journal of Nursing Management, Vol. 25 No. 6, pp. 407-420.

McKenzie, J., van Winkelen, C. and Grewal, S. (2011), "Developing organizational decision-making capability: a knowledge manager's guide", Journal of Knowledge Management, Vol. 15 No. 3, pp. 403-421.

Massaro, M., Dumay, J. and Garlatti, A. (2015), "Public sector knowledge management: a structured literature review", Journal of Knowledge Management, Vol. 19 No. 3, pp. 530-558.

Massingham, P., Massingham, R. and Pomering, A. (2018), "Designing a knowledge management system for social services not-for-profit organizations", International Journal of Knowledge Management, Vol. 14 No. 3, pp. 69-81.

Mohajan, H.K. (2016), "An analysis of knowledge management for the development of global health", American Journal of Social Sciences, Vol. 4 No. 4, pp. 38-57.

Moher, D., Liberati, A., Tetzlaff, J. and Altman, D. (2009), "Preferred reporting items for systematic review and meta-analyses: the PRISMA statement", British Medical Journal, Vol. 339, p. 2535.

Mura, M., Lettieri, E., Radaelli, G. and Spiller, N. (2013), "Promoting professionals' innovative behaviour through knowledge sharing: the moderating role of social capital", Journal of Knowledge Management, Vol. 17 No. 4, pp. 527-544.

Najmi, K., Kadir, A.R. and Kadir, I.A. (2017), "Mediation effect of dynamic capability in the relationship between knowledge management and strategic leadership on organizational performance accountability", International Journal of Law and Management, Vol. 60 No. 2, pp. 517-529.

Nicolini, D., Powell, J., Conville, P. and Martinez-Solano, L. (2008), "Managing knowledge in the healthcare sector: a review", International Journal of Management Reviews, Vol. 10 No. 3, pp. 245-263.

Nonaka, I. and Takeuchi, H. (1995), The Knowledge-Creating Company, Oxford University Press, New York, NY.

Nuno-Solinis, R. (2019), "Advancing towards value-based integrated care for individuals and populations", International Journal of Integrated Care, Vol. 19 No. 4, pp. 1-3.

Panahi, S., Watson, J. and Partridge, H. (2016), "Conceptualising social media support for tacit knowledge sharing: physicians' perspectives and experiences", Journal of Knowledge Management, Vol. 20 No. 2, pp. 344-363.

Parast, M. and Golmohammadi, D. (2019), "Quality management in healthcare organizations: empirical evidence from the Baldrige data", International Journal of Production Economics, Vol. 216, pp. 133-144.

Porter, M.E., Larsson, S. and Lee, T.H. (2016), "Standardizing patient outcomes measurement", New England Journal of Medicine, Vol. 374 No. 6, pp. 504-506.

Rodriguez, E. and Edwards, J.S. (2014), "Knowledge management in support of enterprise risk management", International Journal of Knowledge Management, Vol. 10 No. 2, pp. 43-61.

Rohajawati, S., Sensuse, D.I., Sucahyo, Y.G. and Arymurthy, A.M. (2016), "Mental health knowledge management: critical success factors and strategy of implementation", Journal of Knowledge Management, Vol. 20 No. 5, pp. 980-1003. 
Schreyögg, V. and Sydow, J. (2010), "Organizing for fluidity? Dilemmas of new organizational forms", Organization Science, Vol. 21 No. 6, pp. 1251-1262.

Sheffield, J. (2008), "Inquiry in health knowledge management", Journal of Knowledge Management, Vol. 12 No. 4, pp. 160-172.

Sibbald, S., Wathen, C.N. and Kothari, A. (2016), "An empirically based model for knowledge management in health care organizations", Health Care Management Review, Vol. 41 No. 1, pp. 64-74.

Simonen, O., Blom, M. and Viitanen, E. (2011), "Knowledge effectiveness and its application in secondary healthcare management", International Journal of Productivity and Performance Management, Vol. 60 No. 8, pp. 797-812.

Spender, J.C. (1996), "Making knowledge the basis of a dynamic theory of the firm", Strategic Management Journal, Vol. 17 No. S2, pp. 45-62.

Spender, J.C. (2008), "Organizational learning and knowledge management: whence and whither?", Management Learning, Vol. 39 No. 2, pp. 159-176.

Spender, J.C. (2014), Business Strategy: Managing Uncertainty, Opportunity, and Enterprise, Oxford University Press, Oxford.

Tamanna. and Sharma, S.K. (2019), "Impact of knowledge management and organizational learning on performance in healthcare sector", International Journal of Emerging Technologies, Vol. 10 No. 4, pp. 416-421.

Van Beveren, J. (2003), "Does health care for knowledge management", Journal of Knowledge Management, Vol. 7 No. 1, pp. 90-95.

Von Krogh, G. (1998), "Care in knowledge creation", California Management Review, Vol. 40 No. 3, pp. 133-153.

Williams, P.M. (2012), "Integration of health and social care: a case of learning and knowledge management", Health \& Social Care in the Community, Vol. 20 No. 5, pp. 550-650.

Xiao, Y. and Watson, M. (2017), "Guidance on conducting a systematic literature review", Journal of Planning Education and Research, Vol. 39 No. 1, pp. 93-112.

\section{Further reading}

Barney, J. (1991), "Firm resources and sustained competitive advantage", Journal of Management, Vol. 17 No. 1, pp. 99-120.

Drucker, P.F. (1999), "Knowledge-worker productivity: the biggest challenge", California Management Review, Vol. 41 No. 2, pp. 79-94.

Evans, J.M., Brown, A. and Baker, G.R. (2015), "Intellectual capital in the healthcare sector: a systematic review and critique of the literature", BCM Health Services Research, Vol. 15, pp. 556-569.

Orzano, A., Mclnerney, C., Scharf, D., Tallia, A. and Crabtree, B. (2008), "A knowledge management model: implications for enhancing quality in health care", Journal of the Association for Information Science and Technology, Vol. 59 No. 3, pp. 489-505.

Penrose, E. (1959), The Theory of the Growth of the Firm, John Wiley \& Sons, New York, NY.

Popa, I. and Stefan, S.C. (2019), "Modeling the pathways of knowledge management towards social and economic outcomes of health organizations", International Journal of Environmental Research and Public Health, Vol. 16 No. 7, pp. 1114-1135.

Ragab, M. and Arisha, A. (2013), "Knowledge management and measurement: a critical review", Journal of Knowledge Management, Vol. 17 No. 6, pp. 873-901.

\section{Corresponding author}

Tuomas Hujala can be contacted at: tuomas.hujala@gmail.com 


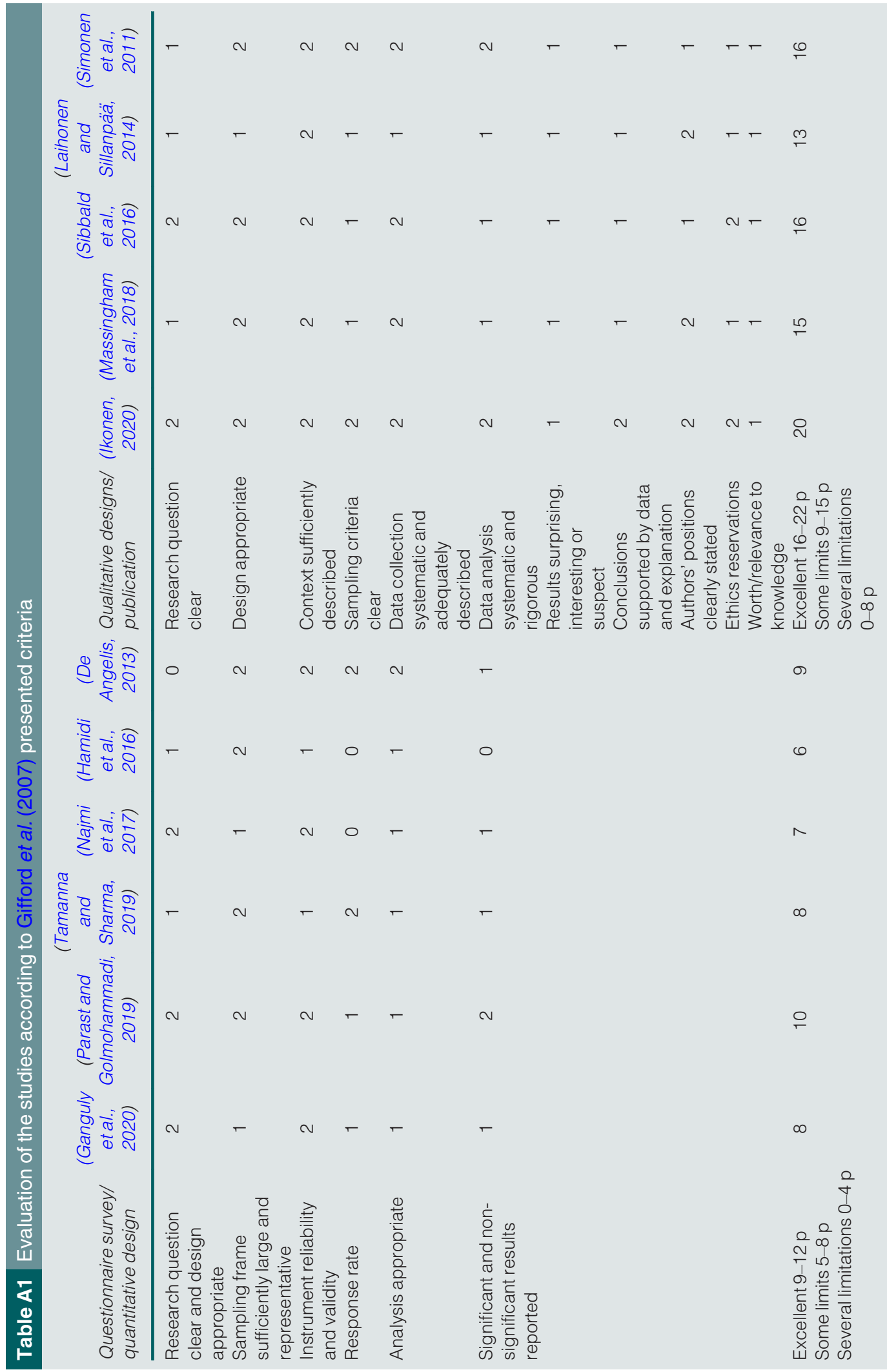

